
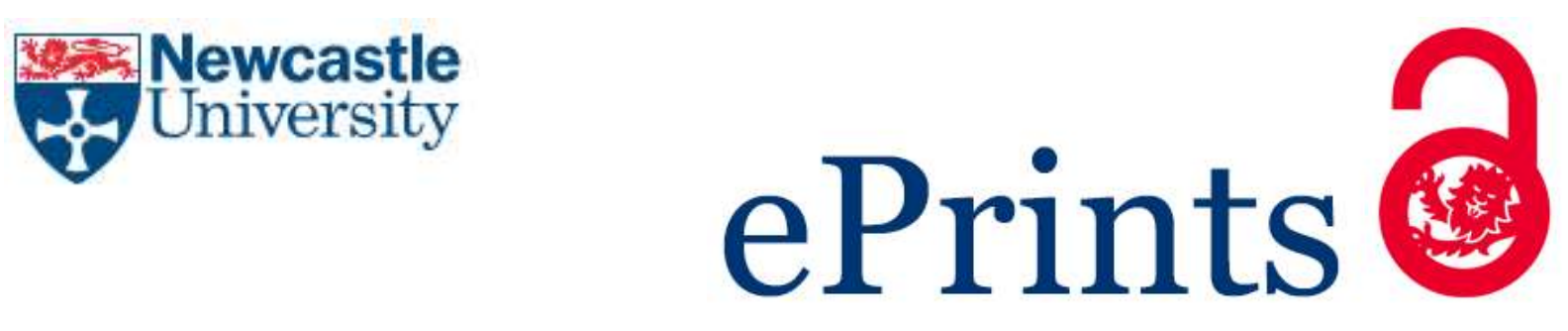

Hewett CJM, Quinn PF, Wilkinson ME. The Decision Support Matrix (DSM) Approach to Reducing Environmental Risk in Farmed Landscapes. Agricultural Water Management 2016, 172, 74-82.

\title{
Copyright:
}

(c) 2016. This manuscript version is made available under the CC-BY-NC-ND 4.0 license

DOI link to article:

http://dx.doi.org/10.1016/j.agwat.2016.03.008

Date deposited:

$27 / 06 / 2016$

Embargo release date:

29 October 2017

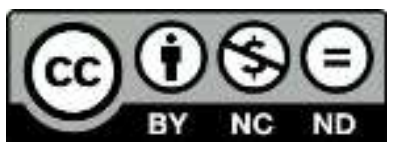

This work is licensed under a

Creative Commons Attribution-NonCommercial-NoDerivatives 4.0 International licence 


\section{The Decision Support Matrix (DSM) Approach to Reducing Environmental Risk in Farmed Landscapes}

Caspar J M Hewett ${ }^{1}$, Paul F Quinn ${ }^{1}$, Mark E Wilkinson ${ }^{2}$

${ }^{1}$ School of Civil Engineering and Geosciences, Newcastle University, Newcastle upon Tyne, NE1 7RU, United Kingdom

${ }^{2}$ The James Hutton Institute, Craigiebuckler, Aberdeen, AB15 8QH.

\section{Abstract}
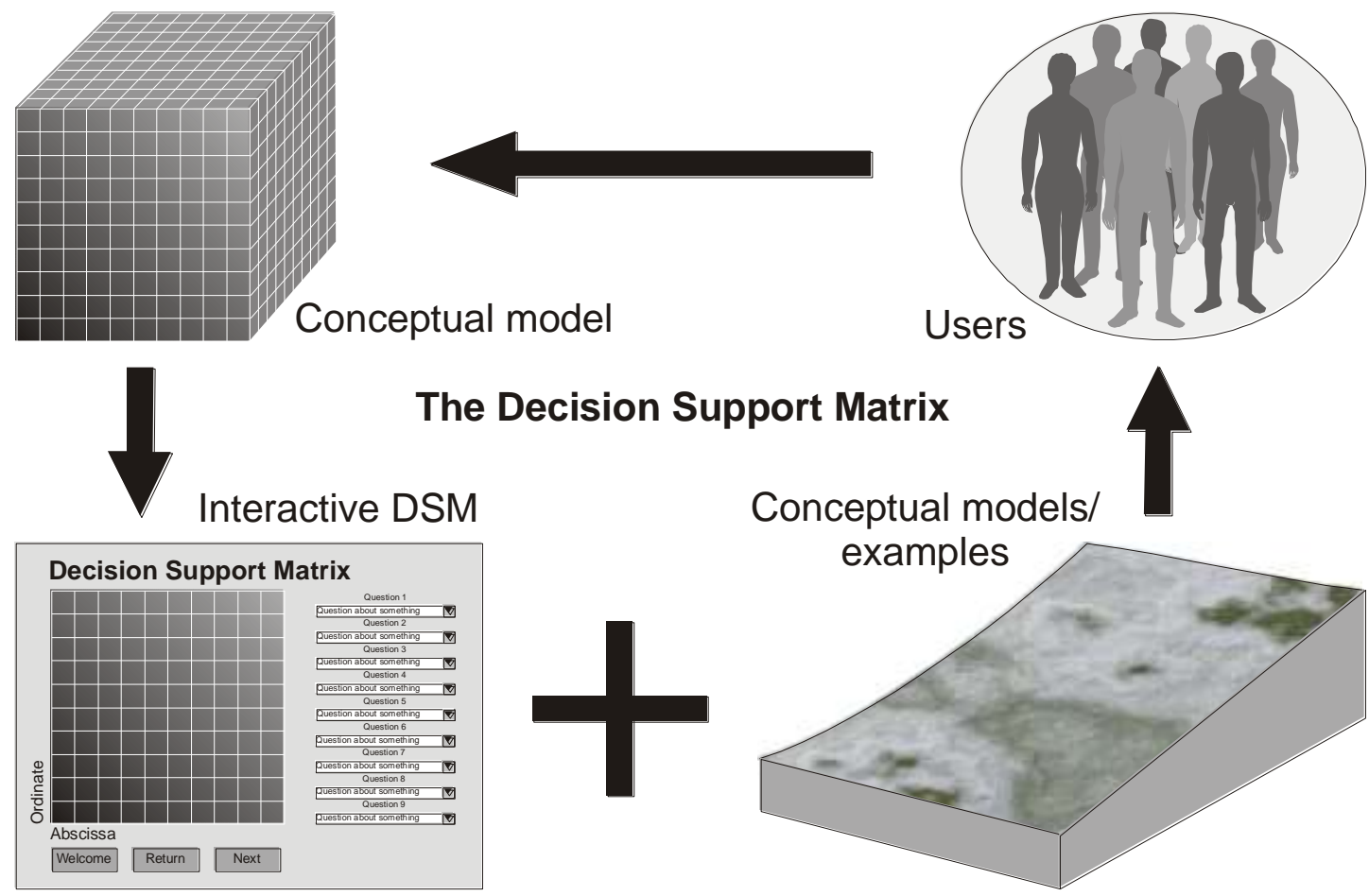

Modern intensive farming is an essential reality of modern life which brings major benefits but results in environmental pressures in constant need of solution, from increased flood risk and soil erosion to nutrient and pesticide export. The Decision Support Matrix (DSM) approach described here utilizes visualization and communication tools to help reduce environmental risk in farmed landscapes. Drawing on methods from physical and human geography, from mathematical modelling to participatory action research, the approach captures research expertise and local knowledge in forms accessible to farmers, land-use managers, planners and policy-makers. Conceptual models, easy-to-use interactive tools and examples of good and bad practice are co-developed by researchers and stakeholders, 
resulting in tools that enable practitioners to better understand the risks associated with specific land-use practices and assess measures to attenuate those risks. Most importantly it encourages users to take steps to reduce environmental risks.

This paper sets out the philosophy underpinning the DSM approach and describes the tools developed. Examples are given of how the approach has been applied successfully to phosphorus and nitrate export, and to flood risk associated with arable and livestock farming.

Keywords: environmental risk, decision support, farming, visualization, communication, modelling, participatory action research, land management, decision support matrix, DSM

\section{Highlights}

- Modern farming practises result in environmental pressures within rural catchments.

- Effective problem solving has to involve links between research and stakeholders.

- The Decision Support Matrix (DSM) approach helps reduce risk in farmed landscapes.

- Research expertise and specialist knowledge of multiple stakeholders are captured.

- The approach fuels creative problem-solving leading to plans for action.

\section{Acknowledgements}

As a part of a long-term collaboration with the Environment Agency of England and Wales covering numerous projects we would like to acknowledge their input and support.

We would also like to acknowledge the following bodies: Engineering and Physical Sciences Research Council (EPSRC) for funding the SEAL project; European Commission Seventh Framework Programme for funding Waterweb (Water in the Western Balkans); Defra for funding FD2114 Flood Management project

\section{Introduction}

There are many environmental pressures within rural catchments which need to be addressed urgently. As global demand for land and food increases, negative trade-offs 
between farming and the environment are becoming harder to avoid especially under predicted climate change scenarios. It is thus increasingly important to find ways of reducing environmental impacts whilst maintaining agricultural production and the economic viability of farms (Foresight 2011, McGonigle et al. 2014). In Europe, this is situated in a legislative framework within which multiple pressures must be addressed simultaneously. For example, the Habitats Directive (Council Directive 92/43/EEC) promotes the maintenance of biodiversity by requiring European Union (EU) Member States 'to take measures to maintain or restore natural habitats and wild species at a favourable conservation status' (JNCC, 2015); the EU Water Framework Directive (WFD) of 2000 (2000/60/EC) aimed to achieve 'good ecological status in all waterbodies by 2015'; and the Floods Directive (2007/60/EC), which came into effect in 2007, required states to prepare preliminary flood risk assessments for all river basin districts by 2011, followed up with flood hazard maps in 2013. By 2015, Member States should have flood risk management plans, ready to link into the next cycle of river basin management plans (2016-2021) (European Commission, 2010). Intense farming makes a major contribution to problems such as increased flood risk, soil erosion and poor water quality in rural catchments (O'Connell et al. 2004, 2007, Heathwaite et al. 2005 and CIRIA 2014). This means that there is great potential for agricultural practitioners to play a significant role in reducing multiple risks through better land-use management (Alphen and Lodder 2006, Grabs et al. 2007, Shrubsole 2007, Everard et al. 2009, WMO 2009, Rouillard et al. 2014). Greater understanding by farmers, land managers, practitioners and policy-makers of the ways in which farmed landscapes contribute to risks and the ways in which those risks might be mitigated can be an essential component in improving practice. However, it is important to recognise that stakeholders such as farmers have a wealth of knowledge which can contribute to better understanding of the processes, practices and potential solutions to problems. The co-production of knowledge can be a key to successful intervention (Wakeford, 2010). Recent more integrated approaches to land and water management take account of this, with natural scientists, sociologists, economists, farmers and regulators all contributing knowledge that can assist in resolving agriculturally-derived issues (Hewett et al. 2010, Oliver et al. 2012).

Further, there is a need to attempt to solve problems with more holistic solutions at multiple scales. Winter et al. (2011) argue that the overwhelming focus on integration at a catchment 
level has led to a neglect of the importance of the sub-catchment (i.e. smaller sub-units within a catchment) as an equally appropriate unit of hydrological analysis (e.g Buck et al., 2004). They suggest that many of the management decisions relevant to water quality are made by land occupiers and, therefore, that the identification of relevant socio-spatial units - the 'private spaces' of land holdings - may be as important or more important to the effective management and planning of water resources as catchment-level planning (Winter et al., 2011). Issues such as cross-sectoral policy making (e.g. agriculture, forestry), land-use planning and integrated ecosystem service management (e.g. water management, nature protection, tourism) make it necessary to involve multiple stakeholders (Sterk et al. 2009). Increasing demands from a public that is scrutinizing decision-making regarding land-use management and its effects on environmental conditions and ecosystem services add additional complexity (Newham et al. 1999, Messner et al. 2006, Milligan et al. 2009, Furst et al. 2010).

There is little doubt that in recent years there had been a significant shift in stakeholderscientist relationships from one of knowledge transfer to one of knowledge exchange, learning and two-way communication of information and advice (Wakeford, 2010, Welch et al. 2014, Maynard, 2015). This is a positive development for interdisciplinary researchers with ambitions to build credible agricultural Decision Support Systems and needs to be embraced (Oliver et al. 2012).

The term Decision Support System (DSS) usually refers to computer-based information systems used for recording, storing, processing and disseminating information to support group or individual decision-making (Burstein and Holsapple 2008, Diez and Mclntosh 2009, Volk et al. 2010). In the past, DSS have been defined as computer-based tools that assist managers with solving ill-structured problems (Morton 1971, Sprague and Carlson 1982, Loucks 1995, de Kok et al. 2009). The purpose of agricultural DSSs is to translate wider policy concerns for sustainable agriculture and water resources under climate change into operational, flexible and adaptive 'on the ground' responses (Oliver et al. 2012). In the field of landscape and river basin management, most DSSs make it possible to draw information from geographical information systems and/or supply interdisciplinary multi-criteria analyses of the hydrological, ecological and economic consequences of different management strategies, based on pre-calculated scenarios or model coupling (Burstein and Holsapple 
2008, Lautenbach et al. 2009). However, historically there has been poor uptake of such systems by stakeholders such as farmers (McCown 2002) and few are currently used to inform policy or to drive policy analysis (Van Delden et al. 2011, Oliver et al. 2012). One major reason for this is that many DSSs are developed by technical experts who are removed from potential end-users such as farmers, land managers and policy-makers, resulting in tools that are complex and difficult to use. There is often also a sense of distrust in models and tools developed in isolation from practitioners. Further, a lack of involvement of local stakeholders can result in modelling outcomes that are neither understandable to them nor help to answer their questions and hence fail to lead to improved environmental management (Dupas et al. 2015). Thus, there is a real need for DSSs that are accessible, trusted and easy to use. The Decision Support Matrix (DSM) approach aims to fulfil that need by bridging the gap between scientists, policy makers and practitioners. The approach is a collaborative one, encouraging a sense of ownership in end-users. It results in tools where the problems and solutions are readily recognised by the practitioners and decision-makers at whom they are aimed. As a consequence the tools tend to get used more readily. The DSMs developed to date have been applied to agricultural systems. They combine expert hydrological evidence with local knowledge of runoff patterns (Hewett et al. 2004, Hewett et al. 2009, Hewett et al. 2010, Wilkinson et al. 2013). They are effective communication tools that have helped guide the way to real interventions (Posthumus et al. 2008, Wilkinson et al 2014).

This paper describes the philosophy and development of the DSM approach. The approach applies human and physical geographic approaches to resolve a variety of environmental problems in particular those resulting from modern intensive farming such as nutrient pollution and flooding. It helps to assess, manage and improve understanding of risk from a multi-stakeholder perspective and proposes solutions to problems drawing on knowledge from practitioners, policy-makers and researchers from multiple disciplines. Examples of how the DSM approach has been applied to specific environmental problems are presented, along with the specific tools developed to address those problems. One DSM, the Nitrate Export Risk Matrix $\left(\mathrm{NO}_{3} \mathrm{RM}\right)$, is presented in detail to convey the concepts underpinning the DSM approach. 


\section{The DSM approach}

The DSM approach involves the development of tools that help visualize and communicate the risks associated with different farming practices and make it possible to explore options to manage runoff. It developed in recognition of the fact that a number of environmental problems such as flooding, erosion and nutrient pollution arise from the alteration of the catchment hydrological cycle (O'Connell et al., 2007). Increases in the intensity of farming play a critical role in exacerbating these problems. It is thus vital that underlying processes and practices are better understood.

A DSM is not a single tool, but is rather a set of tools including examples of good and bad practice, simple tools for assessing specific fields and practices, and advice on interventions to improve outcomes.

The underlying philosophy behind the DSM approach is that effective problem solving has to involve partnerships between researchers and stakeholders. Discussion between primary stakeholders, such as farmers, residents and local traders, secondary stakeholders such as legislative bodies, local and national authorities, and others such as scientists and the research community, is essential in developing the tools. Knowledge and experience are shared and fed into tools that capture and convey problems and potential solutions. The approach draws on methods from human and physical geography. There are two primary theoretical strands underpinning the approach: a set of hydrological principles and Participatory Action Research (PAR) (Chambers, 1994, Brydon-Miller et al. 2003, Hall, 2005, Kindon et al. 2007).

DSMs are described as DSSs in the inclusive sense defined by Power (1997), i.e. they are simply information systems that support decision making. According to Alter's taxonomy for DSS, a DSM fits in the category "suggested model" in that it leads to a suggested decision for a fairly well-understood task (Alter, 1980; Hewett et al., 2010).

There are four key elements to the DSM approach, which are outlined here and discussed in more detail below:

1. Conceptual models: These provide better understanding of the factors which impact on risk. The two principle types of conceptual models employed are: (i) diagrams 
capturing extremes; and (ii) the two- or three dimensional matrices onto which risks are mapped;

2. Interactive tools: These help users to understand better how different practices impact on risk;

3. Stakeholder engagement using a PAR approach: Conceptual models and interactive tools are developed through direct engagement with stakeholders, ensuring that the examples and language used makes sense to end-users and that the knowledge and experience of stakeholders and researchers are embedded in the tools;

4. Iterative development: ensures that the tools improve over time with stakeholder feedback.

The approach can play a pivotal role in getting from science and first-hand knowledge of farming practices to policy. Its advantages are its simplicity and clarity, in particular the visual nature of the conceptual models; shared ownership/co-production of knowledge; and the open source free availability of the tools produced. The need for such tools is clear (e.g. CIRIA 2013).

The DSM approach has been applied successfully to agricultural systems in the UK over a number of years, resulting in a number of DSMs that relate to specific environmental problems. These include the Phosphorus Export Risk Matrix (PERM) (Hewett et al. 2004; Hewett et al. 2010), the Floods and Agriculture Risk Matrix (FARM), of which there are arable and livestock versions (available from http://research.ncl.ac.uk/thefarm) (Wilkinson et al. 2013) and the Nitrate export Risk Matrix ( $\mathrm{NO}_{3} \mathrm{RM}$ - pronounced 'norm') (described in this paper).

The DSMs for agricultural systems presented here are designed to show the current conditions of the land and describe extremes of land-use management within a hydrological and agricultural land-management context. Despite uncertainty, the tools do contribute to stakeholders having greater confidence in making decisions to make landscapes more resilient. DSMs have been taken up widely in the UK by bodies such as the Environment Agency for England and Wales (EA) and the Department for the Environment, Fisheries and Rural Affairs (Defra), and have been successfully employed within wider decision support frameworks alongside modelling at multiple scales (Hewett et al. 2010) 
Originally the DSM evolved from studies that used physically-based models and the output of risk-based modelling frameworks. For example, work on phosphorus (P) losses was captured in the study of Whitehead et al. (2007), where the physically-based model INCA (Wade et al., 2002) was run for a number of land-use management scenarios. The mapping of different $P$ loss patterns was captured in a simple visual form. The results then informed stakeholders of how $\mathrm{P}$ losses were occurring and which specific management options might be considered to reduce those losses. Researchers were able to the link $\mathrm{P}$ loss patterns to the physical properties of the soil and hydrology parameters in a rigorous manner. Similarly in the Defra/EA FD2114 study (O'Connell et al., 2004) the relative change in runoff rates arising from agricultural activity was captured in a prototype version of the FARM tool. The DSM approach was used by the study to facilitate discussion between researchers, practitioners and regulators. Moreover, the FARM tool was linked directly to catchment runoff models and to flood risk (e.g. Packman et al. 2004, Owen et al. 2014). Using early versions of the FARM, end users were asked to assess if farming was having a low, moderate or high impact on runoff rates. The DSM thus encapsulated the findings of the study in a simple visual form. Together these studies helped to establish the form of the DSM as a means to visualize and communicate the results of more detailed models.

An added benefit of note is that some mitigation measures have the potential to simultaneously: reduce flood risk and soil erosion; improve water quality and ecological status; and increase carbon capture and storage. While there is a lack of quantitative data on how effective specific measures are in decreasing particular risks at the catchment scale, there is a wealth of qualitative knowledge in the research community and amongst stakeholders from which the DSM approach draws. Simple-to-use tools encapsulating holistic thinking and problem-solving agendas can and does lead to solutions to multiple problems.

\subsection{Conceptual models of environmental problems}

The DSM approach relies on the use of conceptual models of processes and the specialist and local knowledge of multiple stakeholders including end users. There are two principle types of conceptual model used in the DSM approach:

1. The concept of the matrix itself (Figure 1), and;

2. Example scenarios of a variety of land management practices. 


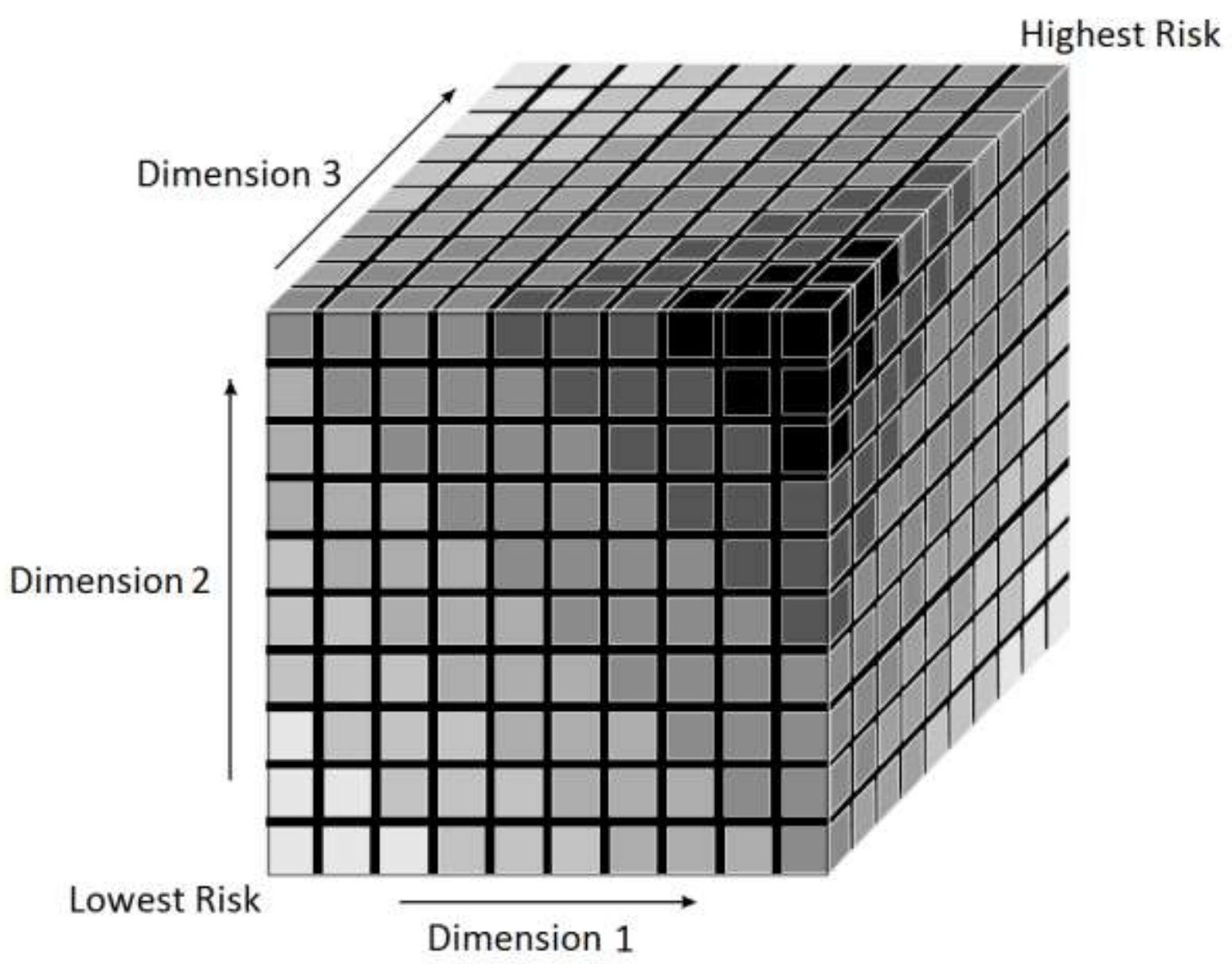

Figure 1. Generic DSM with three dimensions

Figure 1 shows a generic DSM with three dimensions. The concept of the DSM is simply that of plotting the level of risk for a particular site or set of practices onto a matrix with 2 or 3 axes. One corner of the matrix represents the lowest risk and another the highest risk. The use of axes representing different dimensions of activity or practice is important as it helps the user to distinguish between the risks associated with the different dimensions. Examples of these dimensions for specific DSMs include:

- 3D PERM: Flow connectivity; Fertiliser application and soil management; Soil type (Figure 2)

- 3D $\mathrm{NO}_{3} \mathrm{RM}$ : Denitrifying/topography; Nitrate available to transport; Soil Properties (Figure 2)

- 2D NO${ }_{3} \mathrm{RM}$ : Flow connectivity; Nitrate available to transport

- 2D FARM: Flow connectivity; Infiltration and storage 
Note that three of these examples have a flow connectivity dimension in common. This is because flow connectivity is a key area where interventions at the field or farm scale can make a big difference to reducing nutrient loss and flood risk (e.g. CIRIA 2013, Houses of Parliament 2014).
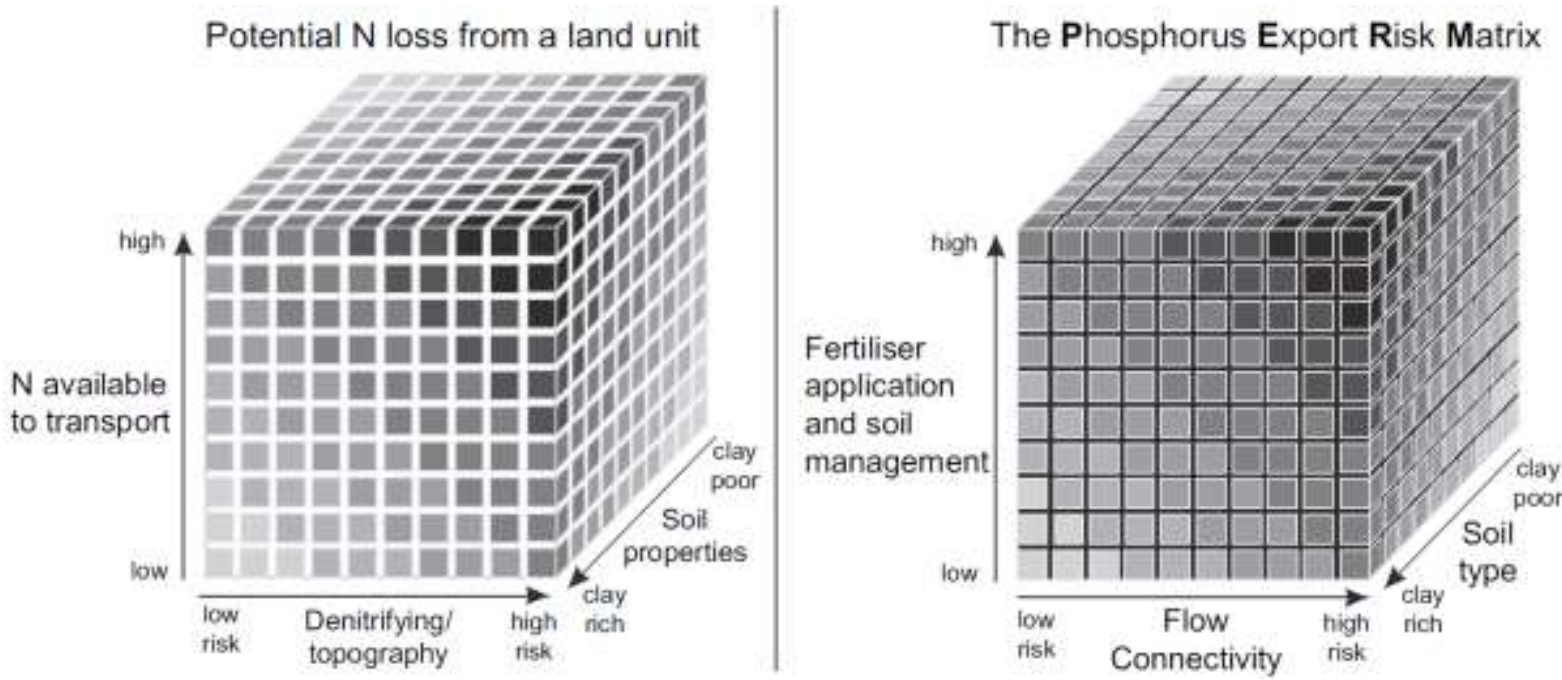

Figure 2. Three dimensional versions of the $\mathrm{NO}_{3} \mathrm{RM}$ and PERM

In the case of the PERM, which was the first DSM to be fully developed (Hewett et al. 2004, Heathwaite et al. 2005), the decision was made in the course of tool development to reduce the number of dimensions from three to two. This decision, made collectively by stakeholders and researchers in stakeholder workshops, was based on four factors:

1. The farmer or land use manager has little or no control over soil type in a particular field, nor the option to change it.

2. Although there is some soil spatial heterogeneity, the soil type within a specific field does not generally vary a great deal.

3. It was agreed that the riparian area and the channel are the key locations to target in risk management and thus making this the focus of the DSM helps keep the message clear about the type of mitigation measures proposed.

4. It is significantly simpler to develop tools (see for example the discussion of interactive tools below) for two axes than three.

A simplifying assumption is thus made that the soil properties do not vary greatly within a particular field, which is the scale at which the interactive tools described below are designed 
to operate. Thus for each field we concentrate on one soil type, a riparian area and the channel. Similar decisions were made for the $\mathrm{NO}_{3} \mathrm{RM}$ and FARM for pragmatic reasons.

It should be noted that we recognise a plan of action to reduce risk should focus on areas of higher risk and that soil type is a risk factor. We thus propose that a broader plan of action which does take account of soil type should be part of a mitigation strategy. Such a plan would identify areas of higher risk using a variety of tools and evidence. This is precisely the approach taken in projects that have used DSMs - they are used alongside models, data and local knowledge and are not intended to be used in isolation (Heathwaite et al. 2005, Hewett et al. 2004, 2009, 2010, Wilkinson et al. 2013).

The second class of conceptual model consists of a set of example scenarios that illustrate a particular set of land management practices and runoff management options, see for example Figures 3 and 4. Runoff scenarios are presented visually as diagrams of individual fields. Each DSM has at least two such scenarios representing the highest and lowest levels of risk. Further scenarios representing intermediate levels of risk have been developed for some DSMs (see for example Posthumus et al. 2008). Each scenario has an associated risk level on the matrix, which is usually presented alongside the diagram (Figure 3 and 4). These examples are designed to show both how current conditions cause problems downstream and how systems are vulnerable to changes in climate and land-use intensification. Diagrams are used instead of photographs to ensure the land unit is conceptual and is not based on an actual place. The diagram captures all the significant land use and hydrological components but must also be recognisable by the end user as realistic. The diagrams are designed for use both in the interactive tools described below and in a workshop setting as a focus for discussion. 

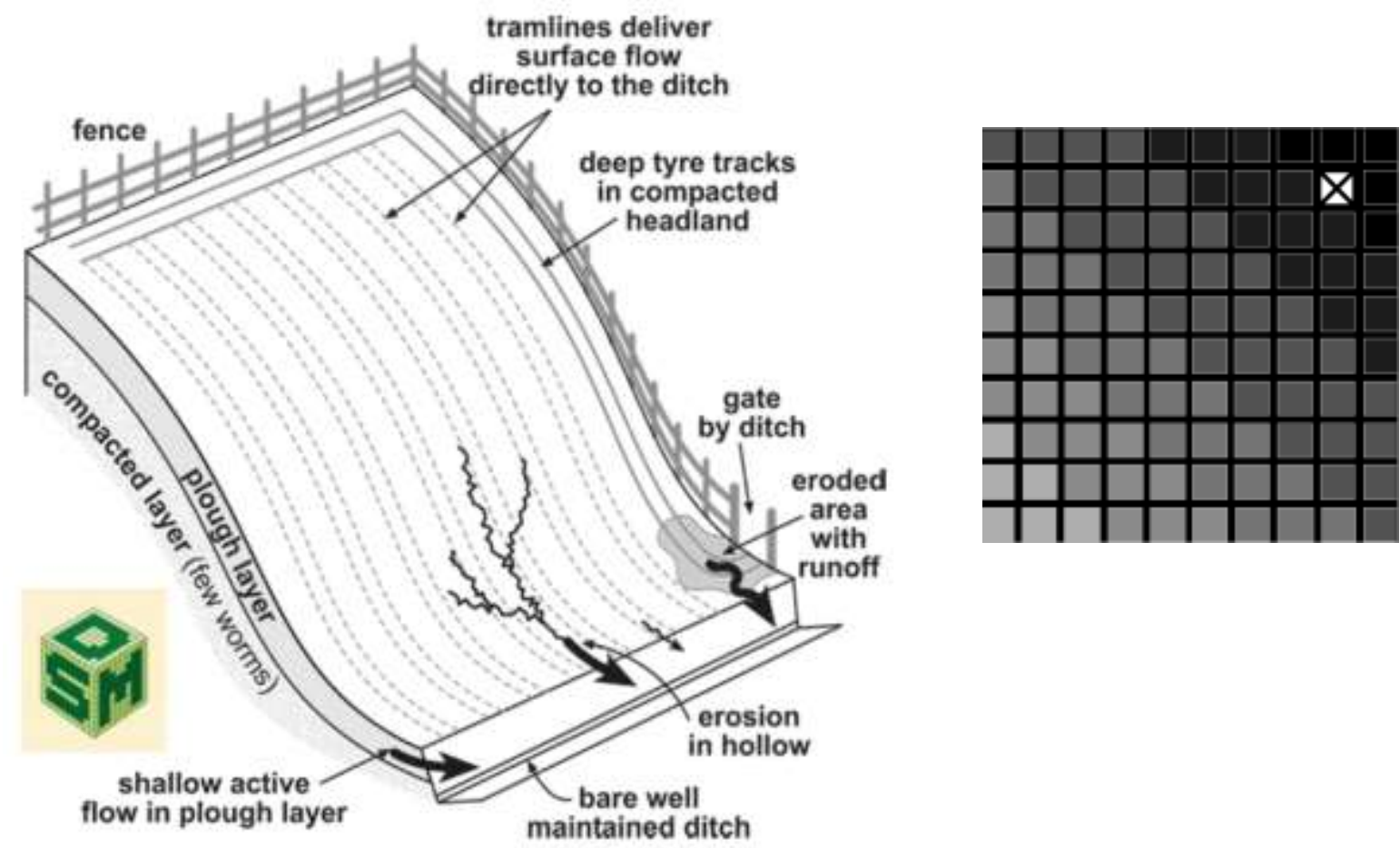

Figure 3. High flow-connectivity, high risk due to fertiliser application
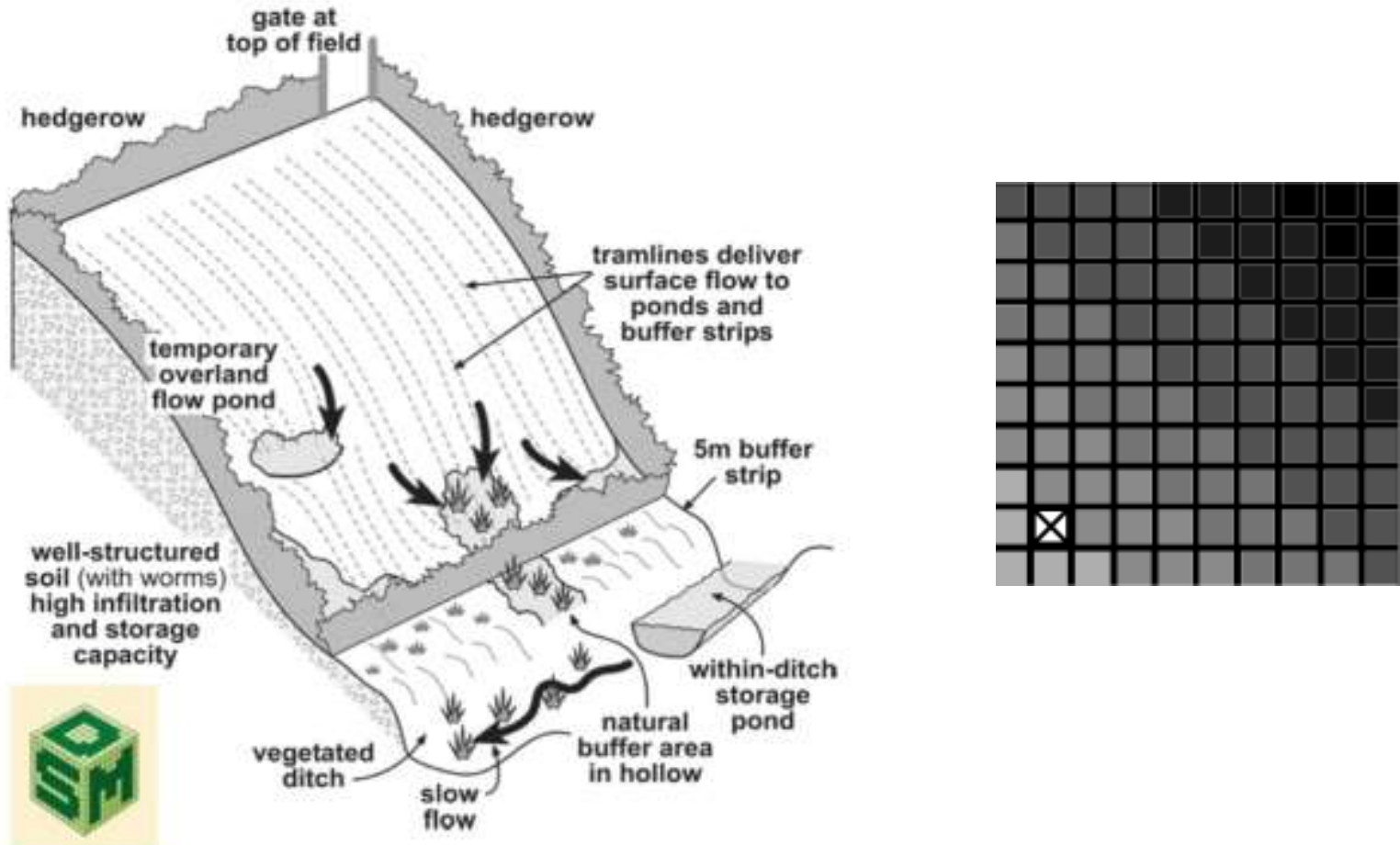

Figure 4. Low flow-connectivity, low risk due to fertiliser application 


\subsection{Interactive tools}

Interactive tools are developed which allow the user to explore management options and assess the level of risk associated with a particular set of practices. The user is presented with a series of questions which are intended to apply to a particular land unit. The user answers the questions either in accordance with current practice or to assess potential future practice. A risk level is generated based on the answers given which is plotted on the matrix, providing a simple representation which is easy to read and interpret. By answering the questions in different ways for the same land unit the user can assess numerous land use and runoff management options to lower risk. The objective is to encourage policy makers, catchment managers and farmers to produce resilient local landscapes at minimal cost. Note that, as well as questions related to current practice, interactive DSMs include questions related to agrienvironmental measures that can be introduced to reduce risk, see for example questions 8 to 10 in Table 2. This allows the user to see how the introduction of such measures could reduce risk at a particular field or site.

The tools employ a ranking methodology combined with a simple mapping to generate the risk plot. A nominal scoring system is used to rank higher or lower runoff risk. Engagement with stakeholders suggested that values or weightings for the questions should be avoided and that the tools should rely on simple rankings and relative risk. This is in keeping with findings of other researchers such as Kim and Lee (2014) who point to the problems associated with a 'subjective weighting process'. Thus the questions are equally weighted across all the interactive tools generated to date.

The interactive DSMs are intended primarily for use within a stakeholder workshop context, although they can be used as stand-alone tools by end users such as farmers and land use managers (for example, the tools have been used by the Environment Agency for England and Wales). With this in mind, the inclusion of visual examples of good and bad practice such as those shown in Figures 3 and 4 are essential components of the tools. As Schwilch et al. (2012) point out in their discussion of Sustainable Land Management (SLM), good software that incorporates visual and interactive tools can aid transparency and enable 'moderators and stakeholders to focus on judgements, choices, and discussions rather than on extensive calculations.' (Schwilch et al. 2012). The interactive DSMs discussed here have been 
developed as Microsoft Excel spreadsheet-based tools. Figure 5 shows a screenshot of the interactive $\mathrm{NO}_{3} \mathrm{RM}$ with some of the questions answered, giving a risk plot on the matrix.

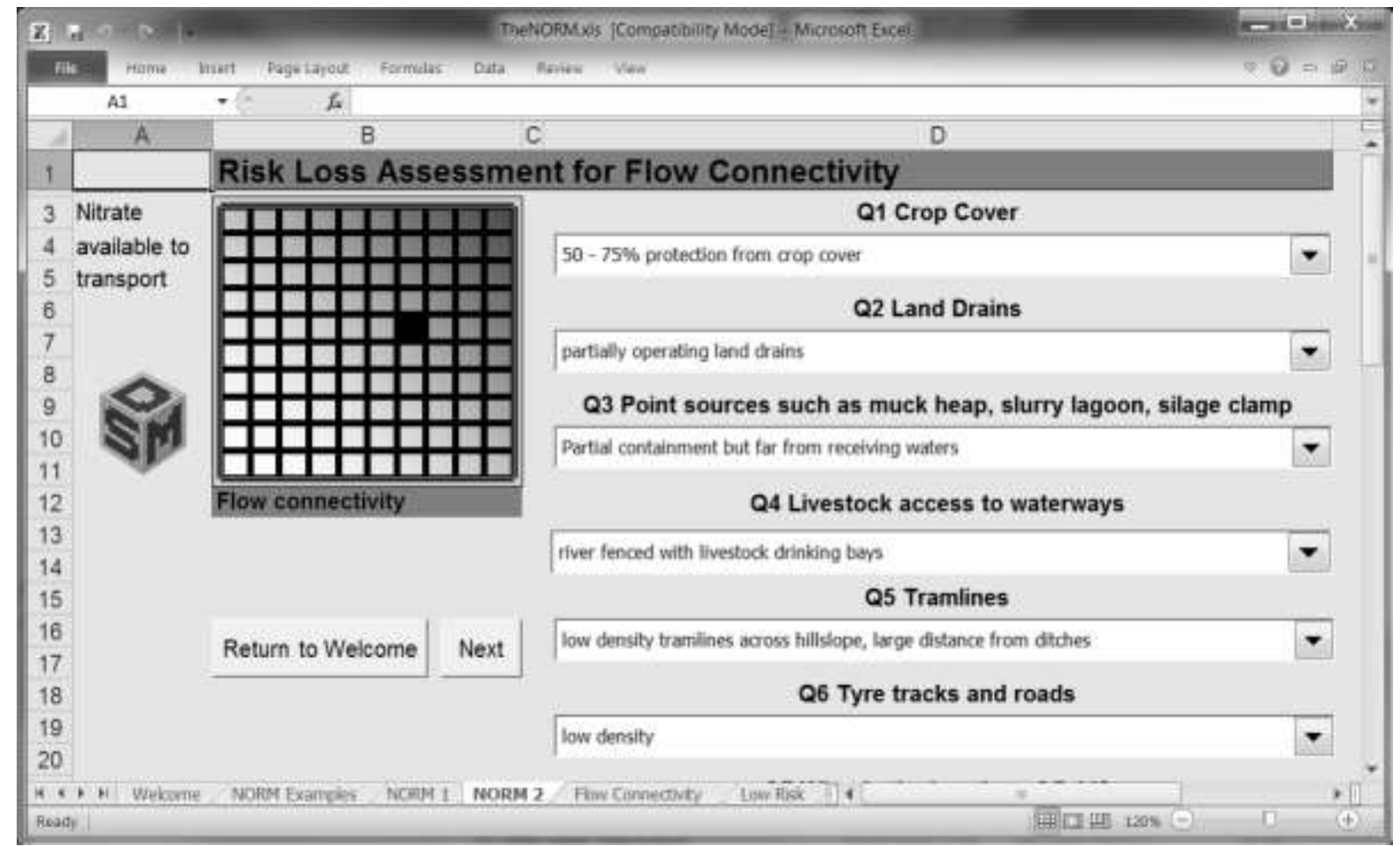

Figure 5. Screenshot of the interactive $\mathrm{NO}_{3} \mathrm{RM}$

Complete sets of questions for a number of DSMs can be found in the literature, for example questions in the interactive PERM can be found in Hewett et al. (2004); and those in the FARM tool can be found in Wilkinson et al. (2013).

A complete set of the questions found in the interactive $\mathrm{NO}_{3} \mathrm{RM}$ tool are reproduced in Tables 1 and 2 as an example. The questions are shown in the shaded rows and the options which can be selected by the user are in the white rows below each question. The two axes used for the interactive $\mathrm{NO}_{3} \mathrm{RM}$ are 'Nitrate available to transport' and 'flow connectivity'.

Table 1. Risk Loss Assessment for $\mathrm{N}$ available to transport - questions on the $\mathrm{NO}_{3} R M$ 's vertical axis

Q1 N loading: How much $\mathbf{N}$ do you intend to apply?

Options: 1. more than $275 \mathrm{~kg} / \mathrm{ha} ; 2$. between 200 and $275 \mathrm{~kg} / \mathrm{ha} ; 3$. between 150 and $200 \mathrm{~kg} / \mathrm{ha} ; 4$. between 100 and $150 \mathrm{~kg} / \mathrm{ha} ; 5$. between 0 and $100 \mathrm{~kg} / \mathrm{ha} /$ none 


\section{Q2 What type of organic fertiliser do you apply?}

Options: 1. high N manures, e.g. poultry, slurry; 2. farmyard manure / sludge cake; 3. composted manure;

4. sludge pellets/granules; 5 . low $\mathrm{N}$ substrates, e.g. municipal compost; none

\section{Q3 When do you apply your organic fertiliser?}

Options: 1. Autumn, no crop; 2. Autumn, with crop; 3. Winter; 4. Summer; 5. Spring; 6. not applicable

Q4 If you use inorganic fertiliser on wheat/barley what is soil type?

Options: 1. shallow over chalk or limestone (55\% efficiency); 2 . medium, clay, silty, organic peaty (60\% efficiency); 3. Light sand soils (70\% efficiency); 4. not applicable

\section{Q5 Application Efficiency}

Options: 1. Very low, e.g. no splash plates, uncalibrated spreading; Medium, e.g. splash plates for muck spreaders; High, e.g. GPS for PKNW, use of specialist equipment, injection of manures; No application

\section{Q6 For how much of year is there a growing crop?}

Options: < 6 months; 6 - 8 months; 8 - 10 months; 10 - 12 months; all year ley; all year permanent pastures

\section{Q7 SNS index}

Options: $6 ; 5 ; 4 ; 3 ; 2 ; 1$

\section{Q8 Soil Management Practices}

Options: Poor soil management; no BFP or soil management; some BFP methods adopted; full adherence to BFP; full adherence to BFP \& extra evidence of runoff/infiltration management; no more tillage of soil

\section{Point sources of $\mathbf{N}$}

\section{Q9 Point sources such as muck heap, slurry lagoon, silage clamp}

Options: No containment/cover near to ditch or other access to receiving waters; Partial containment with location risk i.e. access to receiving waters; No containment but far from receiving waters; Partial containment but far from receiving waters; Fully lined/contained; none

\section{Q10 Livestock access to waterways}

Options: Full access i.e. livestock in river, no fencing; no fencing but restricted access e.g. steep banks; watercourse crossing with water gates; river fenced with livestock drinking bays; no stock access - trough drinking provided 
Table 2. Risk Loss Assessment for Flow Connectivity - questions on the $\mathrm{NO}_{3} R M$ 's horizontal axis

\section{Q1 Crop Cover}

Options: bare soil September - February; small amount of crop cover; stubble or fast growing cover crop; 50 - 75\% protection from crop cover; $100 \%$ crop cover in early winter; natural grassland or forest

\section{Q2 Land Drains}

Options: full land drains in full working order; full land drains in reasonable condition; full land drains in poor condition; partially operating land drains; a few old land drains; no land drains

\section{Q3 Point sources such as muck heap, slurry lagoon, silage clamp}

Options: No containment/cover near to ditch or other access to receiving waters; Partial containment with location risk i.e. access to receiving waters; No containment but far from receiving waters; Partial containment but far from receiving waters; Fully lined/contained; none

\section{Q4 Livestock access to waterways}

Options: full access i.e. livestock in river, no fencing; no fencing but restricted access e.g. steep banks; watercourse crossing with water gates; river fenced with livestock drinking bays; no stock access - trough drinking provided; no livestock

\section{Q5 Tramlines}

Options: dense tramlines in direction of slope connected directly to ditches; dense tramlines in direction of slope partially connected to ditches; dense tramlines in direction of slope but large distance from ditches; medium density tramlines across hillslope, large distance from ditches; low density tramlines across hillslope, large distance from ditches; no tramlines

\section{Q6 Tyre tracks and roads}

Options: high density with clear evidence of surface flow reaching the ditch; medium to high density with evidence of surface flow; medium density but with evidence of surface flow; low to medium density; low density; no tyre tracks or roads

\section{Q8 Buffer Zones}

Options: 0: no buffer zones, e.g. on a man-made ditch; -1: very small riparian zone, e.g. on a river bank; -2 : some buffer zones e.g. 1-2m riparian strips; -3: some buffer zones e.g. 2-10m riparian strips; -4: large buffer zones e.g. >10m riparian strips; -5: large buffer zones especially in zones of flow concentration e.g. hollows

\section{Q9 Wetlands}

Options: 0: no wetlands and no water-logging zones; -1: small wetlands and water-logging zones; -2: medium wetlands and water-logging zones; -3: large wetlands and water-logging zones; -4: a small designed 
constructed wetland processing all the runoff from field; -5: a large designed constructed wetland processing all the runoff from field

\section{Q10 Ponds}

Options: 0 : no ponds; -1: some temporary ponds seen during storms; -2 : some existing ponds, some temporary ponds seen during storms; -3 : small designed and constructed ponds to trap/filter sediment; -4 : medium designed and constructed ponds to trap/filter sediment; -5: large designed and constructed ponds to trap/filter sediment

It should be noted that, while slope is included in the PERM (see Hewett et al. 2010) and FARM tools (see Wilkinson et al. 2013), it was decided to exclude it from the interactive $\mathrm{NO}_{3} \mathrm{RM}$ for similar reasons to the exclusion of a soil type axis: the slope on a particular field cannot be changed significantly and practitioners using the tools are aware that higher slope means higher risk. The argument is that a question should only be included if it relates to factors for which mitigation measures can be implemented. This was agreed with stakeholders, although it may be that a question related to slope would be included in future versions of the tool should users agree it would be a useful addition.

\subsection{Stakeholder engagement}

The DSM approach was developed to show the nature of the problems associated with specific farming practices, such as nutrient export from farmland and flood generation, and to suggest strategies that will help to resolve these (Hewett et al., 2004; Quinn, 2004; Hewett et al., 2009). Discussion between primary and secondary stakeholders, scientists and researchers is essential in developing the tools and is a core element of the DSM approach. Drawing on the PAR approach (Chambers, 1994, Brydon-Miller et al. 2003), shared knowledge generation is a key to the success of the tools (Wakeford, 2010, Whitman et al. 2015). It encourages a shared sense of ownership of any tools produced, be they examples of good and bad practice, or individual questions used in the interactive tools. There are a myriad of participatory techniques that could be used including presentations, public hearings; webpages; interviews; questionnaires; participatory mapping; focus groups; citizen juries; cognitive maps; role-playing; multi-criteria analysis and scenario analyses (Rowe \& Frewer, 2000, Luyet et al. 2012). We favour the stakeholder workshop option because it is one of the 
few participatory techniques that involves all four of the following: Consultation; Collaboration; Co-decision; and Empowerment (Luyet et al. 2012).

DSMs are co-designed through the participatory process and continue to evolve through ongoing engagement. The tools produced need never be considered as finished tools as they are always open to revision in the light of new knowledge, new insights and new users. For example, the tools could adapt to new future policies such as new agri-environment schemes, although some scientific process understanding would be needed related to the new measure. Given the need to engage with diverse groups with a wide knowledge-base and experience the DSM avoids the pitfalls of a formal DSS approach. The DSM approach enhances knowledge exchange by incorporating local knowledge, resulting in tools that can help shape opinion and debate. The underlying concepts of hydrology and farming must be solid but detailed knowledge of the local landscape, practice and future management is brought in by the end-users. In all cases the DSM is used as the initial engagement tool for farmers, practitioners and policy makers. This thinking tool has been used effectively in projects to foster knowledge exchange that has led to real changes in land use management and attitudes to the wider environment.

Each of the existing DSMs have been developed in this way and discussions of the stakeholder engagement involved in their development can be found in the literature: For the PERM, see Hewett et al. (2004), Hewett et al. (2009), Hewett et al. (2010), and for the FARM see Posthumus et al. (2008), Wilkinson et al. (2013). In the case of the $\mathrm{NO}_{3} \mathrm{RM}$ some initial thoughts were developed in the course of the EPSRC SEAL project in which the PERM was developed (Hewett et al., 2004, Quinn 2004). However, it was some time later before an interactive $\mathrm{NO}_{3} \mathrm{RM}$ was developed. In 2007, the Environment Agency (EA) commissioned work to look at data sets, models and tools to help nutrient pollution management entitled 'Making Information Available for Integrated Catchment Management.' The usefulness of the PERM was recognized by the $\mathrm{EA}$ and the need for an interactive $\mathrm{NO}_{3} \mathrm{RM}$ was identified.

The $\mathrm{NO}_{3} \mathrm{RM}$ shares a number of common questions with the PERM since the same hydrological processes are involved. However, there was a clear need to tailor the tool to reflect land use practices and the current science related to nitrate losses. The primary differences between nitrate- and phosphorus- related question arise because: 
1. Nitrate is applied to land in a number of different forms;

2. Nitrate is more soluble and moves in a different way to phosphorus, giving rise to different mobilisation risks;

3. The particulate loss of nitrate is much less significant than for phosphorus and hence the influence of overland flow is much smaller (though not completely absent).

The greatest difference is the number of different forms of nitrate application (1. above): for example, there is bag fertilizer, farmyard manure and slurry, all of which can be highly mobile in the soil. The science behind the tool was already well established (Rigby et al., 2009) and has been captured in a number of modelling tools such as SUNDIAL (Smith et al., 1996), MAGPIE (Lord and Anthony, 2000) and SWAT (Jayakrishnan et al. 2005). While some of the questions were inherited from the PERM (most notably the hydrological components) and had thus been co-developed with stakeholders, many were developed by research and Environment Agency staff only and have not been subject to the PAR element of the DSM approach, i.e. the discursive, co-productive, iterative stage of the tool development has not been completed. The authors thus consider that this DSM is still in its infancy and would welcome the opportunity to develop it further with a wider range of stakeholders.

\subsection{Iterative development}

The success of the DSM approach relies on the input of a diverse range of stakeholders from researchers and other experts in specific disciplines to practitioners and decision-makers. Thus the iterative element of DSM tool development is essential. Initial tools and examples are developed and discussed by stakeholders. The team, which ideally consists of all the coproducers of knowledge, i.e. all the stakeholders, adapt the tools and examples multiple times until there is agreement that they reflect real practice, are easy to understand, and propose realistic interventions to reduce risk. It is only then that tools should be considered useable decision support tools. Although in many cases there will be a particular point at which development is ceased and the tools are rolled out as 'finished' there is never a reason to consider that further iteration would not be useful. DSMs can and should continue to be adapted to stay in line with current practice and the latest understanding and knowledge. In many cases they should also be tailored to local conditions so that they are as pertinent as 
possible to real conditions in the area in which they are applied. A willingness to think of DSMs as 'living tools' rather than finished products ensures that the tools improve over time.

\section{Conclusions}

Modern intensive farming is an essential reality of modern life which brings major benefits but also results in environmental pressures which are in constant need of solution, from increased flood risk and soil erosion to nutrient and pesticide export. The DSM approach described here captures local knowledge and research expertise in simple visualization and communication tools that can help farmers, land-use managers, planners and policy-makers to better understand the risks associated with specific practices and assess measures to attenuate those risks. Most importantly it also encourages users to take steps to reduce environmental risks. Unlike the conventional methods associated with decision support systems the DSM approach employs the "more radical and democratic mode of knowledge co-production" proposed by Whitman et al. (2015) in which knowledge is co-produced by stakeholders and researchers through participatory action research. This results in tools which have real purchase with end-users, helping to ensure greater take up of the research.

The DSM approach has been applied successfully to phosphorus and nitrate export (Hewett et al. 2004, Quinn 2004, Heathwaite et al. 2005), to flooding in the UK (O'Connell et al 2004., Posthumus et al. 2008, Wilkinson et al. 2013) and catchment management frameworks in Northern England (Wilkinson et al 2014). It has proven to work well alongside other tools including a range of models without delaying or confusing the decision-making process.

As well as extensive use by individual farmers in the UK (for example the FARM tool web page has had over 4000 unique visitors) the DSM approach has had an impact on policy and practice in the UK and internationally. For example

1. The Defra FD2114 project looking at flood risk gave rise to numerous policy recommendations including use of the DSM (O'Connell et al. 2004).

2. The DSM was used as part of the Ripon Multi-objective project to reduce flood risk in the Laver and Skell catchments in the UK (see Posthumus et al. 2008). 
3. It has been incorporated into a multi-scale framework for decision support (Hewett et al. 2009) which was adopted by UNESCO HELP (Hydrology, Environment, Life and Policy) programme.

4. The approach has been applied in the Western Balkans (Hewett et al. 2010).

5. The Defra 'Making Space for Water' project co-funded development of the DSM as a tool for use by the Environment Agency of England and Wales (EA).

6. The FARM tool is supported by the EA and is available as an advisory tool on the EA website (Wilkinson et al., 2013).

7. The livestock version of the FARM tool (Animal FARM) has been used in the Morland catchment, Cumbria, UK as part of the UK NERC-funded Environmental Virtual Observatory (EVO) pilot project (Environmental Virtual Observatory 2012, Mackay et al. 2012) and the Defra-funded Demonstration Test Catchment project (Demonstrating Test Catchments 2012, Owen et al. 2012).

8. The DSM was cited in a UK Parliamentary Office of Science and Technology (POST) policy briefing on flood plain management - Houses of Parliament Office of Science and Technology. 2014).

9. The FARM tool is cited in the Scottish Environmental Protection Agency's Natural Flood Management Handbook (SEPA, 2016)

We consider there to be significant scope for more DSM tools to evolve, for example relating to sediment loss, faecal losses and pesticides. Most pertinently the approach is used regularly in informal meetings with Flood Action Groups and farmer meetings in the UK where DSMbased exercises have proven to be powerful tools for binding together diverse stakeholder groups.

The DSM approach fuels creative problem-solving leading to plans for action. It encourages common understanding of what risks are significant and of the consequences of specific decisions and practices, providing a solid foundation for the uptake of better catchment management. There is great potential for the approach to be applied to a wider range of environmental problems and in the context of a much wider set of farming practices in the UK and internationally. 


\section{References}

Alphen, J. V. and Lodder, Q. 2006. Integrated flood management: experiences of 13 countries with their implementation and day-to-day management. Irrigation and Drainage, 55, 159171.

Boardman, J., Ligneau, L., Deroo, A. and Vandaele, K. 1994. Flooding of Property by Runoff from Agricultural Land in Northwestern Europe. Geomorphology, 10(1-4), 183-196.

Boardman, J., Verstraeten, G. and Bielders, C. L., 2006. Muddy Floods. In: Poesen, J. and Boardman, J. eds. Soil Erosion in Europe. Chichester: Wiley, 743-758.

Brydon-Miller, M., Greenwood, D. and Maguire, P. (2003). Why action research? Action Research, 1(1), 9-28.

Buck, O., Niyogi, D. K. and Townsend, C. R. 2004. Scale-dependence of land use effects on water quality of streams in agricultural catchments. Environmental Pollution, 130(2), 287-299.

Burstein, F. and Holsapple, C. W. 2008. Decision support systems in context. Information Systems and E-Business Management, 6(3), 221-223.

Chambers, R. 1994. The Origins and practice of participatory rural appraisal. World Development, 22(7), 953-969

CIRIA 2013. Land use management effects on flood flows and sediments - guidance on prediction. In: CIRIA (ed.) FRMRC2 outputs. London, UK: CIRIA.

de Kok, J. L., Kofalk, S., Berlekamp, J., Hahn, B. and Wind, H. 2009. From Design to Application of a Decision-support System for Integrated River-basin Management. Water Resources Management, 23(9), 1781-1811.

Demonstrating Test Catchments, 2012. Demonstrating test catchments: learning from the DTC projects [online]. Available from:

http://www.demonstratingcatchmentmanagement.net/ [Accessed January 2013]

Diez, E. and Mclntosh, B. S. 2009. A review of the factors which influence the use and usefulness of information systems. Environmental Modelling \& Software, 24(5), 588-602.

Dupas, R., Parnaudeau, V., Reau, R., Jeuffroy, M-H., Durand, P. and Gascuel-Odoux, C. (2015) Integrating local knowledge and biophysical modeling to assess nitrate losses from cropping 
systems in drinking water protection areas. Environmental Modelling and Software, 69, 101110.

Environmental Virtual Observatory, 2012. Environmental Virtual Observatory main website [online]. Available from: http://www.evo-uk.org/ [Accessed January 2013]

Everard, M., Bramley, M., Watts, B., Tatem, K. and Appleby, T. 2009. Flood management: from defence to sustainability. Environmental Liability, 2, 35-49.

Evrard, O., Bielders, C. L., Vandaele, K. and van Wesemael, B. 2007. Spatial and temporal variation of muddy floods in central Belgium, off-site impacts and potential control measures. Catena, 70(3), 443-454.

European Commission. 2010. Water Framework Directive. Available from (http://ec.europa.eu/environment/pubs/pdf/factsheets/water-framework-directive.pdf)

Accessed April 2015

Foresight, 2011. The Future of Food and Farming: Final Project Report.

Furst, C., Volk, M. and Makeschin, F. 2010. Squaring the Circle? Combining Models, Indicators, Experts and End-Users in Integrated Land-Use Management Support Tools. Environmental Management, 46(6), 829-833.

Grabs, W., Tyagi, A. C. and Hyodo, M. 2007. Integrated flood management. Water Science and Technology, 56(4), 97-103.

Hall, B. (2005) In from the cold? Reflections on participatory research from 1970-2005, Convergence, 38(1): 5-24, 2005

Heathwaite, A.L., Quinn, P. and Hewett, C.J.M. 2005. Modelling and Managing Critical Source Areas of Diffuse Pollution from Agricultural Land by Simulating Hillslope Flow Connectivity. J.Hydrology, 304, 446-461

Hewett, C. J. M., Doyle, A. and Quinn, P. F. 2010. Towards a hydroinformatics framework to aid decision-making for catchment management. Journal of Hydroinformatics, 12(2), 119-139.

Hewett, C. J. M., Quinn, P. F., Whitehead, P. G., Heathwaite, A. L. \& Flynn, N. J. 2004 Towards a nutrient export risk matrix approach to managing agricultural pollution at source. Hydrol. Earth Syst. Sci. 8 (4), 834-845 
Hewett, C. J. M., Quinn, P. F., Heathwaite, A. L., Doyle, A., Burke, S., Whitehead, P. G. and Lerner, D. N. 2009. A Multi-Scale Framework for Strategic Management of Diffuse Pollution. Environmental Modelling and Software, 24(1), 74-85.

Houses of Parliament Office of Science and Technology - POSTNOTE 2014 Catchment wide flood management; Houses of Parliament POSTnote Number 484.

Jayakrishnan, R. S., Srinivasan, R., Santhi, C., \& Arnold, J. G. 2005. Advances in the application of the SWAT model for water resources management. Hydrological Processes, 19(3), 749-762. Joint Nature Conservation Committee 2008. Council Directive 92/43/EEC on the Conservation of natural habitats and of wild fauna and flora. Available on http://webarchive.nationalarchives.gov.uk/20081107145633/jncc.gov.uk/page-1374 (accessed April 2015)

Kim, H.Y. and Lee H.K. 2014. Enhanced validity and reliability of spatial decision support systems (SDSS) for sustainable transportation decision-making. Applied Geography, 51, 6571

Kindon, S, Pain, R. \& Kesby, M. Participatory Action Research Approaches and Methods: Connecting People, Participation and Place. Routledge, London

Lautenbach, S., Berlekamp, J., Graf, N., Seppelt, R. and Matthies, M. 2009. Scenario analysis and management options for sustainable river basin management: Application of the Elbe DSS. Environmental Modelling \& Software, 24(1), 26-43.

Loucks, D. P. 1995. Developing and Implementing Decision-Support Systems - a Critique and a Challenge. Water Resources Bulletin, 31(4), 571-582.

Lord, E.I. and Anthony, S.G. 2000. MAGPIE: A modelling framework for evaluating nitrate losses at national and catchment scales. Soil Use and Management 16, 167-174.

Luyet, V., Schlaepfer, R., Parlange, M.B., Buttler, A. 2012. A framework to implement Stakeholder participation in environmental projects. Journal of Environmental Management, $111,213-219$

Mackay, E., Beven, K., Brewer, P. Macklin, M., Marshall, K., Quinn, P., Stutter, M., Thomas, N. and Wilkinson, M. 2012. Exchanging environmental information and decision making: 
developing the local Pilot Environmental Virtual Observatory with stakeholder communities. ed. EGU 2012, 2012 Vienna, EGU2012-8339.

Martin, P., Ronfort, C., D., L., Souchere, V. and Sebillotte, C. 2014. Cost of best management practices to combat agricultural runoff and comparison with the local populations' willingness to pay: Case of the Austreberthe watershed(Normandy, France) Land Use Policy, 38, 454-466. Maynard, C.M. 2015. Accessing the environment: Delivering ecological and societal benefits through knowledge integration - The case of water management. Applied Geography, 58, 94104

McCown, R. L. 2002. Changing systems for supporting farmers' decisions: problems, paradigms, and prospects. Agricultural Systems, 74(1), 179-220.

McGonigle, D. F., Burke, S. P., Collins, A. L., Gartner, R., Haft, M. R., Harris, R. C., Haygarth, P. M., Hedges, M. C., Hiscock, K. M. and Lovett, A. A. 2014. Developing Demonstration Test Catchments as a platform for transdisciplinary land management research in England and Wales. Environmental Science Processes \& Impacts, early view.

Messner, F., Zwirner, O. and Karkuschke, M. 2006. Participation in multi-criteria decision support for the resolution of a water allocation problem in the Spree River basin. Land Use Policy, 23(1), 63-75.

Milligan, J., O'Riordan, T., Nicholson-Cole, S. A. and Watkinson, A. R. 2009. Nature conservation for future sustainable shorelines: Lessons from seeking to involve the public. Land Use Policy, 26(2), 203-213.

Morton, M. S. S., 1971. Management decision systems: computer-based support for decision making. Boston: Harvard Business School Publishing.

Newham, L. T. H., Lynch, T. and Plummer, A. A., Success and failure of decision support systems: learning as we go. ed. Proceedings of the American Society of Animal Science., 1999.

O'Connell, P. E., Beven, K. J., Carney, J. N., Clements, R. O., Ewen, J., Fowler, H., Harris, G. L., Hollis, J., Morris, J., O'Donnell, G., Packman, J. C., Parkin, A., Quinn, P. F., Rose, S. C. and Shepard, M. A., 2004. Review of impacts of rural and land use and management on flood generation. Defra, London. 
O'Connell, P. E., Ewen, J., O'Donnell, G. and Quinn, P. F. 2007. Is there a link between agricultural land-use management and flooding? Hydrol. Earth Syst. Sci., 11(1), 96-107.

Oliver, D. M., Fish, R. D., Winter, M., Hodgson, C. J., Heathwaite, L. A. and Chadwick, D. R. 2012. Valuing local knowledge as a source of expert data: Farmer engagement and the design of decision support systems. Environmental Modelling \& Software, 36, 76-85.

Owen, G.J., Perks, M., Benskin, C., Wilkinson, M., Jonczyk, J. and Quinn, P., 2012. Monitoring agricultural diffuse pollution through a dense monitoring network in the River Eden Demonstration Test Catchment, Cumbria, UK. Area, 44 (4) p. 443-453.

Owen, Gareth, Paul Quinn, and Greg O'Donnell. "Integrating observations and models to help understanding how flooding impacts upon catchments as a basis for decision making." EGU General Assembly Conference Abstracts. Vol. 16. 2014.

Packman, J. C., Quinn, P. F., Hollis, J. and O' Connell, P. E., 2004. Short-term improvement to the FEH rainfall-runoff model: Technical background. Review of Impacts of Rural Land Use and Management on Flood Generation. Defra technical report - FD2114.

Posthumus, H., C.J.M. Hewett, J. Morris and P.F. Quinn. 2008. Agricultural land use and flood risk management: Engaging with stakeholders in North Yorkshire, Agricultural Water Management, 95(7), 787-798

Power, D. J. 1997. What is a DSS? DSstar. On-line Exec. J. Data Intensive Decision Support, 1(3).

Quinn, P.F., 2004. Scale appropriate modelling: representing cause and effect relationships in nitrate pollution at the catchment scale for the purpose of catchment scale planning. Journal of Hydrology 291, 197-217.

Rigby, H., Perez-Viana, F., Cass, J., Rogers, M., \& Smith, S. R. 2009. The influence of soil and biosolids type, and microbial immobilisation on nitrogen availability in biosolids-amended agricultural soils-implications for fertiliser recommendations. Soil Use and Management, 25(4), 395-408.

Rouillard, J. J., Reeves, A. D., Heal, K. V. and Ball, T. 2014. The role of public participation in encouraging changes in rural land use to reduce flood risk. Land Use Policy, 38, 637-645.

Rowe, G. and Frewer, L.J. 2000. Public participation methods: a framework for evaluation. Science Technology \& Human Values, 25(1), 3-29. 
Schwilch, G., Bachmann, F. and de Graaff, J. 2012. Decision support for selecting SLM technologies with stakeholders. Applied Geography, 34, 86-98.

SEPA. 2016. Natural Flood Management Handbook. ISBN: 978-0-85759-024-4. Available for download at http://www.sepa.org.uk/media/163560/sepa-natural-flood-management$\underline{\text { handbook1.pdf }}$

Shrubsole, D. 2007. From structures to sustainability: a history of flood management strategies in Canada. International Journal of Emergency Management, 4, 183-196.

Smith, J.U., Bradbury, N.J. \& Addiscott, T.M. 1996. SUNDIAL: A PC-based system for simulating nitrogen dynamics in arable land. Agronomy Journal 88:38-43

Sprague, R. H. and Carlson, E. D., 1982. Building effective decision support systems. Englewood Cliffs, New Jersey: Prentice Hall.

Sterk, B., Leeuwis, C. and van Ittersum, M. K. 2009. Land use models in complex societal problem solving: Plug and play or networking? Environmental Modelling \& Software, 24(2), 165-172.

Van Delden, H., Seppelt, R., White, R. and Jakeman, A. J. 2011. A methodology for the design and development of integrated models for policy support. Environmental Modelling \& Software, 266-279.

Volk, M., Lautenbach, S., van Delden, H., Newham, L. T. H. and Seppelt, R. 2010. How Can We Make Progress with Decision Support Systems in Landscape and River Basin Management? Lessons Learned from a Comparative Analysis of Four Different Decision Support Systems. Environmental Management, 46(6), 834-849.

Wade, A. J., Whitehead, P. G. and Butterfield, D. (2002) The Integrated Catchments model of Phosphorus dynamics (INCA-P), a new approach for multiple source assessment in heterogeneous river systems: model structure and equations, Hydrology and Earth Systems Sciences, 6, 583-606

Wakeford, T. 2010. From transmission to co-inquiry: Future trends in science communication. Japanese Journal of Science Communication 7, 87-93 
Welch, C., Sinha, T. \& Ward, N. 2014. From Knowledge Transfer to Knowledge Exchange and Beyond: the Story of a Community of Inquiry. British Academy of Management Conference 2014

Whitman, G.P., Pain, R. and Milledge, D.G. 2015. “Going with the flow? Using participatory action research in physical geography." Progress in Physical Geography 39(5), pp.1-18 DOI:10.1177/0309133315589707.

Wilkinson, M. E., Quinn, P. F. and Hewett, C. J. M. 2013. The Floods and Agriculture Risk Matrix: a decision support tool for effectively communicating flood risk from farmed landscapes. International Journal of River Basin Management, 11(3), 237-252.

Wilkinson, M. E., Quinn, P. F., Barber, N. J., \& Jonczyk, J. 2014. A framework for managing runoff and pollution in the rural landscape using a Catchment Systems Engineering approach. Science of The Total Environment, 468, 1245-1254.

Winter, M., Oliver, D. M., Fish, R., Heathwaite, A. L., Chadwick, D. and Hodgson, C. 2011. Catchments, sub-catchments and private spaces: Scale and process in managing microbial pollution from source to sea. Environmental Science \& Policy, 14(3), 315-326.

Whitehead, P.G., Heathwaite, A.L., Flynn, N.J., Quinn, P.F., Hewett, C. and Wade, A. (2007) Evaluating the Risk of Non-point Source Pollution from Sewage Sludge: Integrated Modelling of Nutrient Losses at Field and Catchment Scales. Hydrology and Earth Systems Science, 11(1): 601-613.

WMO, W. M. O., 2009. Integrated Flood Management Concept Paper. Associated Programme on Flood Management in association with Global Water Partnership (WMO-No1047). World Meteorological Organisation, Geneva, Switzerland. 